\title{
Remarks on the application of two-dimensional shape factors under severe wear conditions
}

\author{
Giuseppe PINTAUDE ${ }^{1, *}$, Mario COSEGLIO ${ }^{2}$ \\ ${ }^{1}$ Programa de Pós-Graduação em Engenharia Mecânica e de Materiais, UTFPR, Curitiba, PR, Brazil \\ ${ }^{2}$ University of Birmingham, Birmingham, $U K$ \\ Received: 10 May 2015 / Revised: 25 November 2015 / Accepted: 22 January 2016 \\ (C) The author(s) 2016. This article is published with open access at Springerlink.com
}

\begin{abstract}
The use of two-dimensional shape parameters to characterize abrasive particles is a potential approach to express their angularity. Nevertheless, in sliding abrasion, especially in pin abrasion testing, these descriptors could not be suitable for characterizing severe wear of engineering materials such as steels and cast irons. This work compares the applicability of two-dimensional shape parameters in describing severe wear of metals in recent pin abrasion tests with cases where they could have been correlated with the wear rates. Considering these aspects, this work puts in evidence the importance of clogging occurrence and the coated paper structure for a carefully application of shape parameters. In addition, it is proposed a possible relation between the shape parameters and one of the components of the abrasion factor.
\end{abstract}

Keywords: wear; particle shape; sliding abrasion; coated papers

\section{Introduction}

Wear caused by hard particles is strongly affected by the particle shape, as can be observed in the model for the abrasive wear process proposed by Rabinowicz et al. [1] to explain their experimental results. In this model (Eq. (1)), $\mathrm{d} V / \mathrm{d} l$ is the rate of change of volume swept per unit length, $W$ is the load applied by the abrasive, $p$ is the surface hardness and $\theta$ is the semiapex angle of an abrasive particle represented by a circular conical indenter. The shape is characterized by the average cotangent of $\theta$ for each indenter in a system containing $n$ particles. Attempts to estimate the number of particles in contact with the abraded surface can involve either the surface roughness [2] or the number of scratches produced [3].

$$
\frac{\mathrm{d} V}{\mathrm{~d} l}=\frac{W}{\pi p} \frac{1}{n} \sum_{1}^{n} \cot \theta
$$

\footnotetext{
* Corresponding author: Giuseppe PINTAUDE.

E-mail: giuseppepintaude@gmail.com

A preliminary version of this work was presented at the 2nd International Brazilian Conference on Tribology-TriboBr-2014, Foz do Iguaçu, Paraná, Brazil, 2014.
}

Additional evidence of the importance of representing the particle geometry by tridimensional objects is the definition of ploughing component of friction proposed by Goddard and Wilman [4]. For idealized conical particles, for example, the ploughing component of friction $\left(\mu_{\mathrm{p}}\right)$ is defined by Eq. (2), where $p_{\mathrm{m}}$ is the maximum flow pressure of the surface region of the abraded metal, $p_{\mathrm{m}}^{\prime}$ is the dynamic pressure of the metal and $\theta$ semi-apex angle.

$$
\mu_{\mathrm{p}}=\frac{2}{\pi} \frac{p_{\mathrm{m}}^{\prime}}{p_{\mathrm{m}}} \cot \theta
$$

This work discusses the applicability of twodimensional shape parameters in describing severe wear of metals in recent pin abrasion tests [5-7] and compares it with cases where the descriptors correlated well with the wear rates $[8,9]$.

\section{Useful definitions of shape parameters}

Three definitions are presented here and used to characterize abrasive particles. A usual description of 
particle shape is based on how the particle projection differs from a circle. According to Wojnar [10], particle projections can be grouped in three families of shape according to their transition from an initial circle. The first case corresponds to ellipses with different elongations (Fig. 1(a)) and the second represents the conditions where the shape remains rounded while the boundary irregularity increases (Fig. 1(b)). The last case is a combination of the previous, i.e., the particle shape is far from a circle and has a complex boundary (Fig. 1(c)). For each situation it is assumed that there is a most suitable descriptor to characterize the particle shape.

\subsection{Aspect ratio}

The elongation presented in Fig. 1(a) is common in plastically deformed particles due to the action of axial stresses, for example. An efficient manner to measure the elongation is the aspect ratio, usually defined as the ratio between the maximum length (e.g., maximum Feret's diameter) and the corresponding width of the two-dimensional projection of the particle. The

(a)
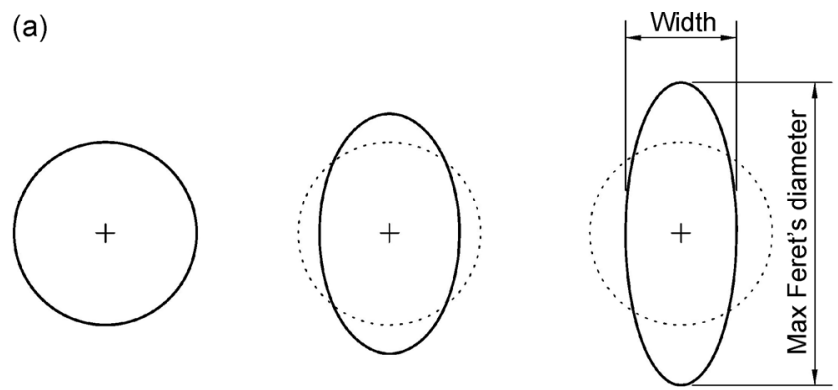

(b)
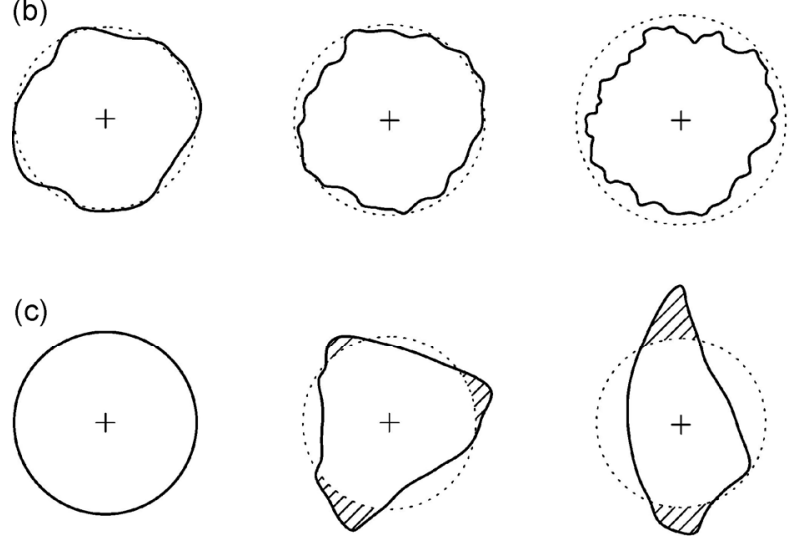

Fig. 1 Particle shape comparison with a circle: (a) ellipses with different elongations; (b) increase in the border irregularity of rounded shapes; (c) combination of the previous cases. Adapted from Ref. [10].
Heywood's elongation ratio is a similar shape descriptor, which also correlates the particle length and width. In some terminologies, both parameters have no differentiation. The aspect ratio definition is illustrated in Fig. 1(a).

\subsection{Form factor}

Form factor is one of the most used parameters to characterize the shape of abrasive particles. It is defined as the ratio between the particle projection area, $A$, and the area of the corresponding circle whose perimeter $L$ equals the particle perimeter (Eq. (3)).

$$
\mathrm{FF}=\frac{4 \pi A}{L^{2}}
$$

This factor seems to be a good solution to detect the border irregularities of rounded particles (Fig. 1(b)). As the particle projection becomes circular the form factor approaches 1 and as the border becomes irregular, its value decreases, as schematically illustrated in Fig. 2.

\subsection{Spike parameters}

Hamblin and Stachowiak $[8,9]$ introduced two parameters to describe the particle angularity. The spike parameter (SP) is based on the representation of the projection of the particle boundary by a series of triangles at different scales. It is assumed that the smaller the apex angle and the higher the size of the triangle, the higher the particle abrasivity. In order to characterize both the angularity and the size of the geometric features present in the particle contour, the spike value of each triangle (sv) is defined according to Eq. (4), where $\phi$ is the apex angle and $h$ is the triangle height (Fig. 3).

$$
\mathrm{SV}=\cos \left(\frac{\phi}{2}\right) h
$$

- Particle perimeter $(L)$

Corresponding circle with perimeter equal to $L$
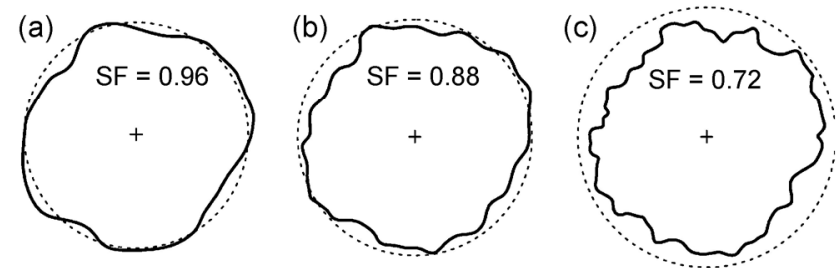

Fig. 2 Particle irregularity detection by shape factor. 


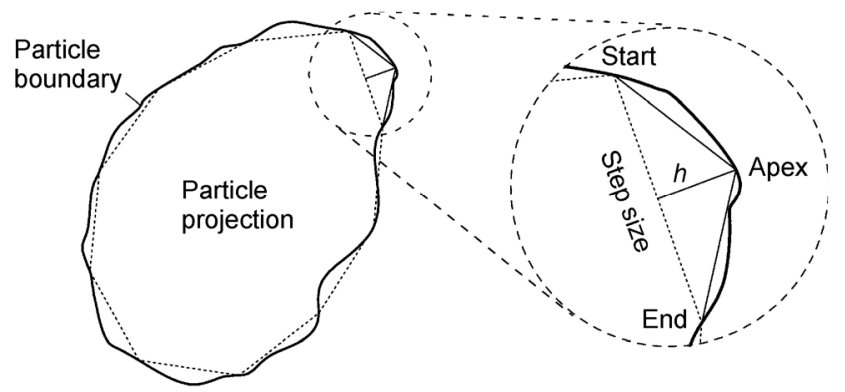

Fig. 3 SP calculation procedure. Adapted from Ref. [8].

For each triangle found, the maximum spike value $\left(\mathrm{sv}_{\max }\right)$ is determined in terms of maximum triangle height $\left(h_{\max }\right)$. The procedure is repeated for different step sizes along the perimeter and for all possible starting points at the border, resulting in an average spike value. The parameter is then determined by Eq. (5), where $m$ is the number of valid sv for a given step size and $n$ is the number of different step sizes considered.

$$
\mathrm{SP}=\frac{1}{n} \sum\left[\left(\frac{1}{m}\right) \sum\left(\frac{\mathrm{sv}_{\max }}{h_{\max }}\right)\right]
$$

The second parameter proposed later by Hamblin and Stachowiak [9], named spike parameter-quadratic fit (SPQ), was developed to quantify particle angularity by detecting geometries potentially favorable for material removal process. The SPQ procedure is schematically represented in Fig. 4. The first step consists in particle centroid localization (point $O$ ). A circle with center at $O$ and radius $r_{\mathrm{m}}$ is positioned, where the radius is determined by averaging all local radius $(r)$ along the particle boundary. Each region outside this circle or "spike" is characterized by the spike value (svq) defined in Eq. (6).

$$
\mathrm{svq}=\cos \left(\frac{\varphi}{2}\right)
$$

The apex angle $\varphi$ is composed of one central angle $(\beta)$ and two side angles $\left(\alpha_{\mathrm{S}}\right.$ and $\left.\alpha_{\mathrm{E}}\right)$. The particle boundary portions between the segments SM and EM are approximated as polynomial functions and the side angles are then obtained by differentiating these functions at M. The SPQ is then obtained by the average value of all valid spike values found for the particle (Eq. (7)). The lower the apex angle the higher the spike value and, consequently, the higher the SPQ and the particle abrasivity.

$$
\mathrm{SPQ}=\left(\frac{1}{n}\right) \sum_{i=1}^{n}\left(\mathrm{svq}_{i}\right)
$$

Hamblin and Stachowiak $[8,9]$ successfully correlated the two spike parameters (SP and SPQ) with the wear of chalk samples. This tested material was selected to avoid any kind of damage to the abrasive grains and to eliminate the transfer of worn material to the counterface. As no correlations were performed with engineering materials, such as steels and cast irons, the present work deeply discusses their applications under these conditions.

\section{Case studies: Glass and alumina coated papers}

Based on a previous investigation [11], the measurements of shape factors for alumina and glass particles extracted from abrasive coated papers are reported in the present work. Twenty particles whose average sizes are $360 \pm 50 \mu \mathrm{m}$ (alumina) and $460 \pm 80 \mu \mathrm{m}$ (glass)
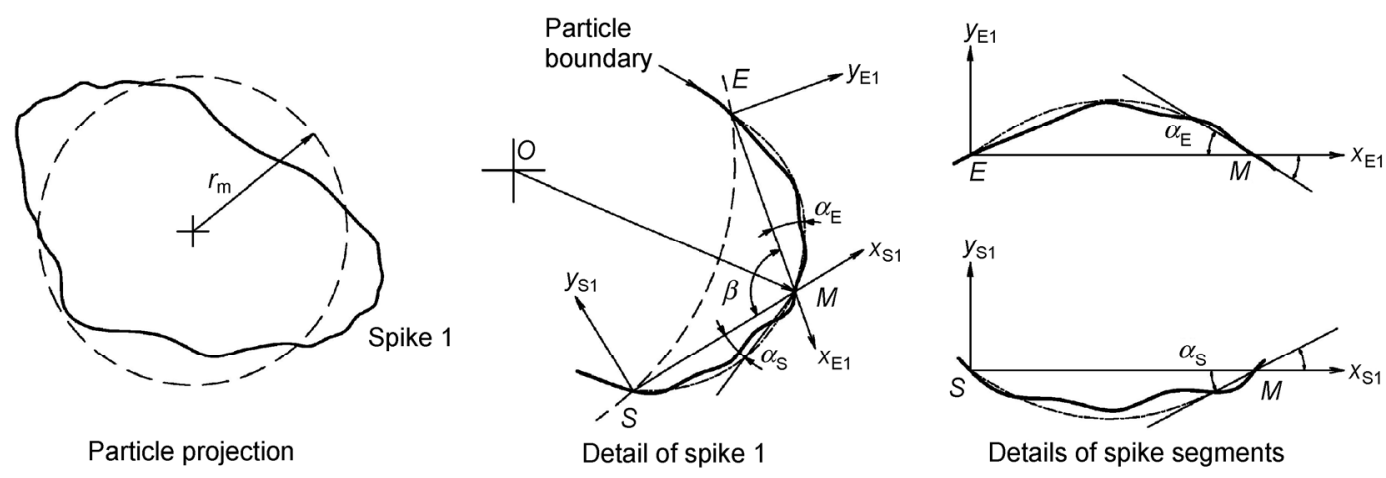

Fig. 4 SPQ calculation procedure: (a) centroid location and $r_{\mathrm{m}}$ definition; (b) detail of spike 1; (c) side angles. Adapted from Ref. [9]. 
were randomly selected. Considering a previous discussion [12], we can sustain that the particle size does not influence the two-dimensional analysis of shape description and then the size effect can be omitted due to its minor significance. The images obtained from optical microscope were submitted to threshold process to convert it to binary images, whose contours are represented in Fig. 5. SPQ was determined using a set of functions in MATLAB's image processing toolbox and algorithms developed following Eq. (7). More details on the routines to determine the aspect ratio (Eq. (1)) and form factor (Eq. (2)) can be found in Ref. [11]. For SPQ (Eq. (7)), the routines can be found in Ref. [13].

Table 1 shows the values of shape descriptors for glass and alumina particles removed from coated papers. None of shape descriptors were able to differentiate between glass and alumina particles, since all average values are significantly similar. These results open a possibility to affirm that their manufacturing processes were similar. Garboczi et al. [14], for example, did not find differences in shape of some rocks, which can indicate that blasting and crushing processes

(a)
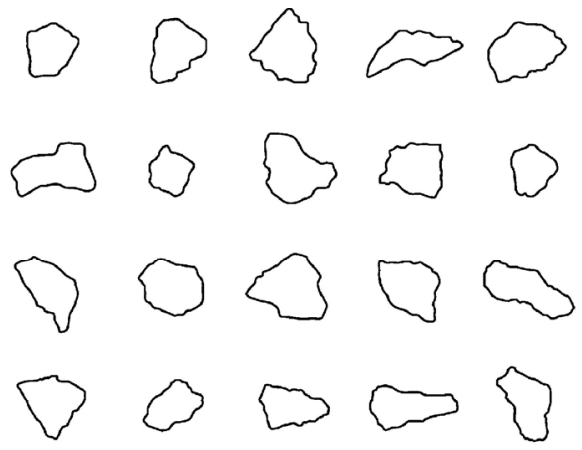

(b)
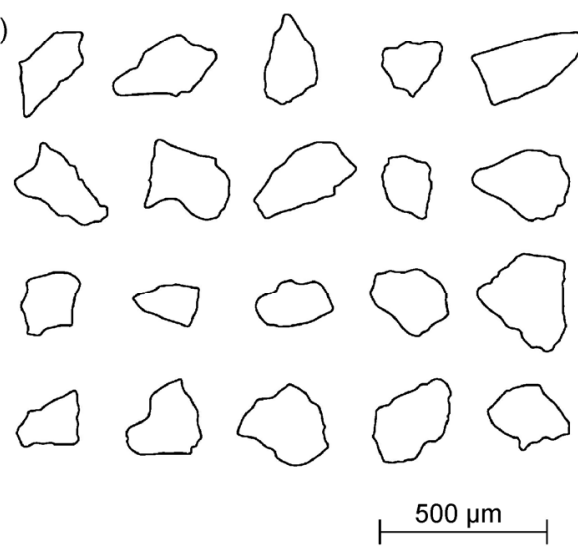

Fig. 5 Binary images of abrasive particles for calculation procedure of shape factors: (a) alumina; (b) glass paper.
Table 1 Shape descriptors values for particles removed from coated papers.

\begin{tabular}{cccc}
\hline Particle & SPQ & Form factor & Aspect ratio \\
\hline Glass & $0.43 \pm 0.15$ & $0.7 \pm 0.2$ & $1.5 \pm 0.3$ \\
Alumina & $0.37 \pm 0.15$ & $0.7 \pm 0.1$ & $1.6 \pm 0.5$ \\
\hline
\end{tabular}

applied to produce them are based on the same breakage mechanism.

In terms of wear behavior, the results of Table 1 creates an expectation that similar wear rates or friction coefficients would be obtained when these particles abrade a same material, keeping constant all other system variables of Eqs. (1) and (2). In addition, similar values may indicate that two-dimensional approach is inherently not able to incorporate the effect of size and hardness to explain pin abrasion results. This limitation was previously discussed by Pintaude [12], where similar shape parameters were unlikely to describe some of the wear results produced by different abrasive sizes.

The results presented in Table 1 will be used to evaluate the correlation between the two-dimensional shape parameters and the wear and friction coefficients obtained by Pintaude et al. [5,6] (Table 2). Two tribological pairs containing glass and alumina as abrasive materials in a pin abrasion test were selected. As can be observed, the values of friction coefficient and wear volume per sliding distance are similar for both systems. In fact, this similarity agrees with the expectation that similar shape factors would cause equivalent tribological behaviors. On the other hand, these pairs exhibit different abrasive hardness-tomaterial hardness ratio. This difference will be evaluated by means of the abrasion factor determined by Eq. (8) [15] where $K$ is the wear coefficient and $\mu_{\mathrm{p}}$ is the

Table 2 Severe wear indicators for different tribological pairs.

\begin{tabular}{ccccc}
\hline $\begin{array}{c}\text { Tribological } \\
\text { pair* }\end{array}$ & $H_{\mathrm{a}} / H$ & $\begin{array}{c}\text { Friction } \\
\text { coefficient }\end{array}$ & $\begin{array}{c}\text { Wear volume } \\
\text { per sliding } \\
\text { distance } \\
\left(\mathrm{m}^{3} / \mathrm{m} \times 10^{-10}\right)\end{array}$ & $\begin{array}{c}\text { Abrasion } \\
\text { factor, } f_{\mathrm{ab}} \\
(\text { Eq. }(8))\end{array}$ \\
\hline $\begin{array}{c}\text { Glass abrading } \\
1006 \text { steel [5] }\end{array}$ & 5.7 & 0.53 & 2.80 & 0.04 \\
\hline $\begin{array}{c}\text { Alumina } \\
\text { abrading 1070 } \\
\text { steel [6] }\end{array}$ & 2.9 & 0.55 & 2.95 & 0.26 \\
\hline
\end{tabular}

*Both tests were performed using 20 N. $H_{\mathrm{a}}$ : abrasive hardness, $H$ : abraded metal hardness. 
ploughing component of the friction coefficient.

$$
f_{\mathrm{ab}}=K / \mu_{\mathrm{p}}
$$

To determine $\mu_{\mathrm{p}}$, the adhesive component of the friction coefficient is assumed to be 0.2 [16], so that this value is subtracted from the total friction coefficient. The difference observed in $f_{\mathrm{ab}}$ is related to a well-known effect that harder materials are associated with higher abrasion factors under severe wear conditions [15-17].

In summary, as the alumina and the glass have similar shape factors (Table 1 ) and the same abrasives caused similar wear rates (Table 2) under severe conditions (high $H_{\mathrm{a}} / H$ ), the difference in $f_{\mathrm{ab}}$ is only justified by the geometry of the worn surface. The $A_{2}$ component of $f_{\mathrm{ab}}$ is schematically represented in Fig. 6 [17] as a constant value, representing in this case the similarity in the wear rates. At the same time, the other component $A_{1}$ is assumed to be variable. This reasoning allows concluding that any twodimensional shape factor should be related only to the $A_{2}$ component and not to the abrasion factor as a whole, as indicated by the literature [18, 19].

Another relevant effect usually reported in pin abrasion testing is the loading of the abrasive papers, where debris are entrapped into the space among the abrasive grains. This effect is more pronounced for soft metals as reported by Ref. [5] for the 1006 steel, where the increase in metal-metal contacts leads to changes on the adhesive component of friction. In addition, and probably more important for this
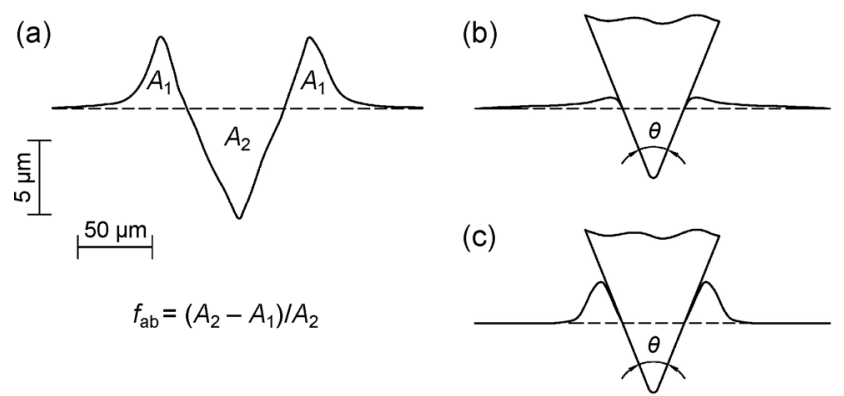

Fig. 6 (a) Definition of abrasion factor, $f_{\mathrm{ab}} . A_{1}$ : the cross section area relative to pileup produced by a single scratch; and $A_{2}$ : the cross section area relative to the groove produced by a single scratch. Adapted from Ref. [17]. (b) Example of a high value of $f_{\mathrm{ab}}$, and (c) example of a low value of $f_{\mathrm{ab}}$. Note the same value of $A_{2}$ for (b) and (c). discussion, the actual geometry of the abrasives in contact with the worn surface can be very different of those grains removed from the coated papers when determining the shape factors, as it can hide important geometric features for the cutting mechanism.

The transfer of metallic debris to the coated papers was also reported by Hamblin and Stachowiak [8] when investigating the wear of aluminum samples. For example, they found that although alumina grains exhibited a high average spike parameter (SP) of 0.36 compared to 0.15 obtained for glass beads, the former produced the lowest wear rates. This unexpected result was justified by the clogging of alumina agglomerate with metallic wear debris. Taking into account the observations presented in the Refs. $[5,20]$ and considering the extensive plastic deformation of metals as an intrinsic phenomenon during severe abrasion-closely related to the clogging occurrencethe used two-dimensional shape factors to describe the severity of a wear system involving coated abrasive papers against engineering materials, such as steels and cast irons, should be done carefully.

Another aspect that deserves a discussion is the relation between the shape factors and the structure of the coated papers. For this purpose the shape factors of twenty particles of glass and alumina particles provided by Coronado et al. [7] were calculated and presented in Table 3. These researchers performed wear tests using $\mathrm{SiC}$, alumina, garnet and glass papers with average size between 60 and $66 \mu \mathrm{m}$. When one observes the surfaces of these coated papers, it is worthwhile the significant difference in the coverage of the surface area found for the glass paper. As previously observed (Table 1), Table 3 shows that none of the shape descriptors were able to distinguish between glass and alumina particles in terms of angularity. In this way, the shape factors are unable to detect different structure of coated papers. A significant aspect observed for the paper with a lower coverage

Table 3 Shape descriptors values for coated papers revealed by Ref. [7].

\begin{tabular}{cccc}
\hline Particle & SPQ & Form factor & Aspect ratio \\
\hline Glass & $0.5 \pm 0.1$ & $0.7 \pm 0.1$ & $1.7 \pm 0.5$ \\
Alumina & $0.5 \pm 0.2$ & $0.7 \pm 0.1$ & $1.9 \pm 0.6$ \\
\hline
\end{tabular}


area is the presence of relatively free particles occupying the regions among the ones attached to the paper. These particles can become three body agents during the wear process, a phenomena already described in Ref. [5].

\section{Conclusions}

From the above discussed results, the following conclusions can be presented:

(1) Two-dimensional shape parameters can be related to a single component of the abrasion factor under severe wear conditions.

(2) The occurrence of clogging is an impeditive for using two-dimensional shape factors describing the wear in sliding abrasion systems, in particular those made use of pin abrasion testing with coated papers.

(3) Two-dimensional shape factors are unable to distinguish coated paper structure, which certainly affects the tribological behaviors.

\section{Acknowledgments}

G. Pintaude acknowledges $\mathrm{CNPq}$ by granting from Project 312385/2014-5.

Open Access: The articles published in this journal are distributed under the terms of the Creative Commons Attribution 4.0 International License (http:// creativecommons.org/licenses/by/4.0/), which permits unrestricted use, distribution, and reproduction in any medium, provided you give appropriate credit to the original author(s) and the source, provide a link to the Creative Commons license, and indicate if changes were made.

\section{References}

[1] Rabinowicz E, Dunn L A, Russell P G. A study of abrasive wear under three-body conditions. Wear 4(5): 345-355 (1961)

[2] Spurr R T. The nature of contact during abrasion. Wear 67(3): 375-379 (1981)

[3] Wang A G, Hutchings I M. The number of particle contacts in two-body abrasive wear of metals by coated abrasive papers. Wear 129(1): 23-35 (1989)
[4] Goddard J, Wilman H. A theory of friction and wear during the abrasion of metals. Wear 5(2): 114-135 (1962)

[5] Pintaude G, Tanaka D K, Sinatora A.The effects of abrasive particle size on the sliding friction coefficient of steel using a spiral pin-on-disk apparatus. Wear 255: 55-59 (2003)

[6] Pintaude G, Bernardes F G, Santos M M, Sinatora A, Albertin E. Mild and severe wear of steels and cast irons in sliding abrasion. Wear 267(1): 19-25 (2009)

[7] Coronado J J, Rodríguez S A, Sinatora A. Effect of particle hardness on mild-severe wear transition of hard second phase materials. Wear 301: 82-88 (2013)

[8] Hamblin M G, Stachowiak G W. A multi-scale measure of particle abrasivity, and its relation to two-body abrasive wear. Wear 190: 190-196 (1995)

[9] Hamblin M G, Stachowiak G W. Description of abrasive particle shape and its relation to two-body abrasive wear. Tribol Trans 39: 803-810 (1996)

[10] Wojnar L. Image Analysis: Applications in Materials Engineering. Boca Raton: CRC Press, 1999.

[11] Coseglio M, Pintaude G. Abrasive particle characterization following different measurements of shape factor. In Proceedings of the 20th International Congress of Mechanical Engineering. Gramado, Brazil, 2009: paper COB09-140.

[12] Pintaude G. Characteristics of abrasive particles and their implications on wear. In New Tribological Ways. Taher G Ed. Rijeka: Intech, 2011: 117-130.

[13] Coseglio M S D R, Moreira P P, Procópio H L, Pintaude G. Analysis of the efficiency of hydroerosive grinding without renewal of abrasive particles. J Manufact Sci Eng 138(3): 031007 (2016)

[14] Garboczi E J, Liu X, Taylor M A. The 3-D shape of blasted and crushed rocks: From $20 \mu \mathrm{m}$ to $38 \mathrm{~mm}$. Powder Technol 229: 84-89 (2012)

[15] Jacobson S, Wallén P, Hogmark S. Fundamental aspects of abrasive wear studied by a new numerical simulation model. Wear 123: 207-223 (1988)

[16] Sin H, Saka N, Suh N P. Abrasive wear mechanisms and the grit size effect. Wear 55: 163-190 (1979)

[17] Buttery T C, Archard J F. Grinding and abrasive wear. Proce Inst Mech Eng 185(1): 537-551 (1970)

[18] Hokkirigawa K, Kato K. An experimental and theoretical investigation of ploughing, cutting and wedge formation during abrasive wear. Tribol Int 21(1): 51-57 (1988)

[19] Zum Gahr K H. Modelling of two-body abrasive wear. Wear 124(1): 87-103 (1988)

[20] Moore M A, Douthwaite R M. Plastic deformation below worn surfaces. Metall Trans A 7(12): 1833-1839 (1976) 


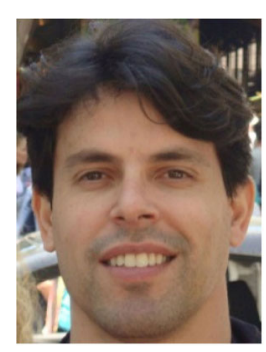

Giuseppe PINTAUDE. $\mathrm{He}$ is a professor in the Academic Department of Mechanics at the Federal University of Technology, Paraná, Brazil. He is also a researcher of the National Research Council $(\mathrm{CNPq})$, Brazil. He received his Doc. Ing. degree in mechanical engineering from the

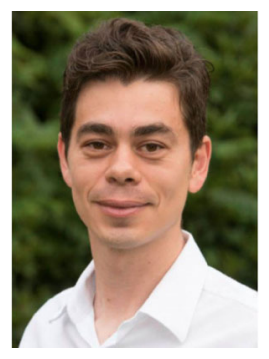

Mario COSEGLIO. He received his bachelor degree in mechanical engineering and his MEng from Federal University of Technology, Curitiba, Brazil, in 2009 and 2013,
University of São Paulo in 2002. In 2015-2016 he worked as a visiting scholar at the School of Metallurgy and Materials, University of Birmingham, UK. He is a member of the Tribology Technical Division of The Brazilian Society for Metals, Materials and Mining. Professor Pintaude's current researches are tribo-corrosion, abrasion, contact mechanics, lubricated wear, and surface treatments.

respectively. He is currently a Ph.D. student at the School of Metallurgy and Materials, University of Birmingham, UK. His research interests include localized corrosion and environmentally assisted cracking of oilfield components. 